\title{
Foetal programming in the pathogenesis of arterial hypertension
}

\author{
Damian Gojowy, Marcin Adamczak, Andrzej Więcek \\ Department of Nephrology, Transplantation and Internal Medicine, Medical University of Silesia, Katowice, Poland
}

\begin{abstract}
Pathogenesis of arterial hypertension is complex and in spite of the decades of studies is not yet entirely understood. In recent years, attention has been paid to the phenomenon of foetal programming and its relationship to arterial hypertension in adult life. It has been shown that low birth weight predisposes to the development of arterial hypertension. The relationship between the number of nephrons and blood pressure and the risk of hypertension also has been found. Blood pressure and the number of nephrons depend on both genetic and environmental factors affecting pregnant females. The aim of this review is to summarize the current knowledge concerning the role of foetal programming in the pathogenesis of arterial hypertension in adults.

key words: arterial hypertension; foetal programming; foetal development

Arterial Hypertens. 2016, vol. 20, no. 4, pages: 228-232

DOI: $10.5603 / A H .2016 .0026$
\end{abstract}

\section{Introduction}

Pathogenesis of arterial hypertension is complex and in spite of the decades of studies is not yet entirely understood. All potential risk factors contributing to the pathogenesis of arterial hypertension can be divided into three groups: genetic factors (e.g. monogenic forms of hypertension), congenital factors (e.g. low birth weight) and acquired factors (e.g. renal artery stenosis). According to the Barker's hypothesis (i.e. foetal programming hypothesis), harmful factors such as limited intake of nutrients, placenta dysfunction, hyperglycaemia and cigarette smoking during pregnancy result in occurrence of chronic diseases such as arterial hypertension, ischaemic heart disease, chronic kidney disease and metabolic syndrome in adult life $[1,2]$. The aim of this review is to summarize the current knowledge concerning the role of

Address for correspondence: Prof. Andrzej Więcek

Department of Nephrology, Transplantation and Internal Medicine,

Medical University of Silesia

40-027 Katowice, Poland, Francuska 20/24

Tel: +48-322552695, Fax: +48-322553726

E-mail: awiecek@sum.edu.pl

M Copyright $(2016$ Via Medica, ISSN 2449-6170 foetal programming in the pathogenesis of arterial hypertension in adults.

\section{Low birth weight}

A low birth weight according to the WHO definition is the weight of live-born infants lower than $2,500 \mathrm{~g}$ or below the $10^{\text {th }}$ percentile for the gestational age (small for gestational age - SGA). A meta-analysis of 20 clinical trials showed $21 \%$ higher risk of arterial hypertension in adult life in subjects with low birth weight compared with those with normal birth weight [3]. Subjects with a birth weight lower than 2,500 g are characterized by $2.6 \mathrm{~mm} \mathrm{Hg}$ higher systolic blood pressure [3].

\section{Kidney development, nephron number and blood pressure}

Intrauterine growth retardation affects the kidney development. There is a lot of evidence that kidney plays a crucial role in pathogenesis of arterial hypertension. Rettig et al. in experimental study trans- 
planted a kidney from a spontaneously hypertensive rats (SHR) to rats with normal blood pressure. After the transplantation normotensive rats (WKR) developed hypertension [4]. In another experimental study, transplantation of the kidney from normotensive donor rats lead to decrease in blood pressure in recipient rat with hypertension [5]. In humans, in the 4.5-year follow-up of 6 patients with chronic kidney disease due to hypertension, after kidney transplantation it was observed not only normalization of blood pressure, but also partial regression of the hypertensive organ complications [6].

A number of both experimental and clinical studies suggest the relationship between low nephron number and arterial hypertension. In humans there is high variability of the number of nephrons between individuals. Puelles et al. in the study of 800 autopsies found that the number of glomeruli in human kidney varies between 210,000 and 2,700,000 [7]. Keller $e t$ al. in autopsy study compared the number of glomeruli in patients with essential hypertension and those without hypertension [8]. They found that the number of glomeruli per kidney was significantly lower in hypertensive patients than in normotensive subjects $(890,869$ vs $1,666,805)$. This observation was confirmed in other study [9]. In humans nephrogenesis is finished in 34 weeks of gestational age and there is no further nephron number increase to the end of life [10]. Therefore, the number of nephrons is determined in the foetal period. Glomerular adaptation to the increased size of the body during growth in humans is through glomeruli hypertrophy, only.

\section{Factors affecting the nephron number}

Manalich et al. performed an autopsy study in newborns. They showed that the number of glomeruli significantly depends on the birth weight [11]. Interestingly, Hughson et al. in another autopsy study have shown that $1-\mathrm{kg}$ increase in the birth weight results in an increase in the number of glomeruli by over 250,000 [12]. Studies on white newborns identified some polymorphic variants of the human tyrosine kinase receptor gene (RET) associated with a reduction by $10-23 \%$ of newborn kidney volume [13]. It has been shown that kidney size correlates positively with the number of glomeruli per kidney $[14,15]$. In Swiss Kidney Project on Genes in Hypertension (SKIPOGH) observational study involving 793 subjects from 205 families it has been shown that the length of the kidney depends on genetic factors in $50 \%$ [16]. Therefore it can be assumed that nephron number depends on environmental factors in the remaining $50 \%$.

\section{Environmental factors}

Different environmental factors may influence nephrogenesis and may affect the foetus' number of nephrons and blood pressure in adult life (Fig. 1). First of all it concerns the amount of protein intake during pregnancy. It was shown that the offspring of mothers who had experienced a limited amount of protein intake during pregnancy were characterized by a lower number of nephrons and higher mean arterial blood pressure $[17,18]$. In various studies, both experimental and clinical, it has been estimated that the reduction of the number of functioning nephron due to reduced protein intake ranged from $11 \%$ to $30 \%$ [19]. In experimental studies on rats, Burdge et al. demonstrated that the protein intake restriction during pregnancy reduced DNA methylation of PPAR alpha gene in the offspring [20]. In addition, such a maternal diet reduced the expression of $\mathrm{AT}_{1}$ and $\mathrm{AT}_{2}$ receptors in the offspring [21]. Another factor contributing to the decrease of the nephrons number in offspring is a vitamin A deficiency during pregnancy [22]. In humans it was shown that there was reduction of the kidney volume in the offspring of mothers who had decreased plasma concentration of vitamin A during pregnancy [23]. Results of experimental studies suggest the negative effects of iron and zinc deficiencies in mothers on the number of nephrons in offspring [24-27]. The number of foetal nephrons is also affected by the

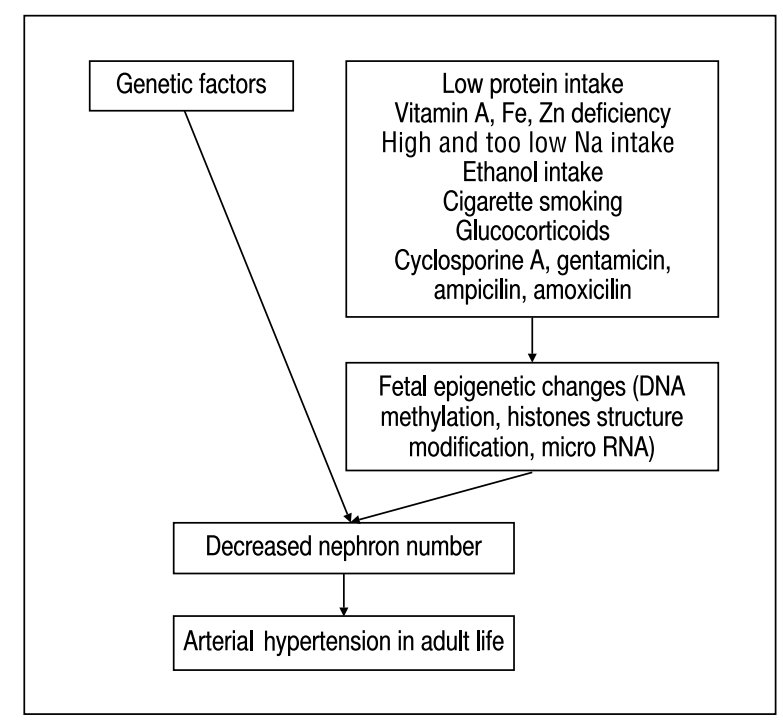

Figure 1. Pathomechanism of foetal programming in the pathogenesis of arterial hypertension 
sodium intake during pregnancy. This relationship is however complex [28]. Both too high and too low sodium intake lead to the nephrons number reduction in offspring. High sodium diet reduced the renin-angiotensin system activity. Intact foetal kidney RAA activity is necessary for the proper kidney growth. On the other hand, too low sodium intake decreases the blood flow through the placenta. Both of these mechanisms seems to affect adversely the number of nephrons in the kidneys of the foetus. It has been shown in the experimental studies that the consumption of ethanol during pregnancy reduces the number of nephrons in the foetus and results in blood pressure increase during adult life [29, 30]. Also cigarette smoking adversely affects the development of foetal kidneys by reducing the number of podocytes, as shown by experimental study in rats [31]. In observational studies in humans systolic blood pressure was increased in those whose mothers smoked cigarettes during pregnancy [32]. Other studies have confirmed an increase of blood pressure both in childhood and in adult life in the offspring of mothers who smoke during pregnancy $[33,34]$. In children of mothers smoking during pregnancy, a reduction of renal volume in ultrasound examination was also observed [35].

\section{Drugs affecting foetal kidney development}

The number of nephrons in the foetus is also affected by several drugs used by pregnant female.

In many experimental and clinical studies the negative effects of glucocorticoids on number of nephrons in the foetus and blood pressure in offspring have been shown [36-39].

Doyle et al. in a cohort study of 210 14-year-old children compared individuals exposed to antenatal corticosteroids with those who did not have such an exposition. Children exposed to corticosteroids during foetal period had higher systolic and diastolic blood pressure [37]. There is expression of $11 \beta$-hydroxysteroid dehydrogenase type 2 in placenta during pregnancy, which protects the foetus against an excessive amount of both endogenous (e.g. severe stress in the mother) or exogenous glucocorticoids [40]. In experimental studies on pregnant rats carbenoxolone, an 11BHSG2 inhibitor, was administered. This resulted in blood pressure increase in the offspring [41]. It was also shown that protein restriction in the diet reduced $11 \beta$-HSD2 activity [42]. Therefore malnutrition during pregnancy may result in the more intensive exposure of foetus on glucocorticoids.
Another drug influencing the development of the kidney in the foetus is calcineurin inhibitor, cyclosporine A. Experimental study in rats has shown that administration of cyclosporine A during pregnancy reduces the number of glomeruli, increases glomeruli volume and increases blood pressure in the offspring [43]. Also, administration of amoxicillin and ampicillin during pregnancy in rats contributed to the deterioration of kidney development in its foetuses [44]. Moreover Gilbert et al. in studies on guinea pigs have shown the negative effect of gentamycin exposition during pregnancy on foetal kidney development [45]. The clinical relevance of these observations needs, however, further studies.

\section{Mechanism of prenatal programming}

It is known that the mechanisms involved in foetal programming are epigenetic. Epigenetic changes involve modification of gene expression without changing the genetic material. They consist of modifying the DNA structure or function by DNA methylation, histones modification and micro RNA.

The most important of epigenetic changes are DNA methylation. Methylation modifies genes' structure by attaching a methyl group to cytosine. These may change the gene expression. In the past few years, some studies have shown a relationship between exposure to nutrients during pregnancy and the change of foetus DNA methylation [46]. Hogg et al. observed increase in DNA methylation in placentas of pregnant women with hypertension compared with women with normal blood pressure [47]. There are some studies that have shown that factors that increase DNA methylation causes the development of cardiovascular disease, including hypertension [48]. Experimental studies on rats have shown that increased folic acid intake during pregnancy enhanced methylation in glucocorticosteroid receptor gene and results in an increase in blood pressure in susceptible offspring [49]. The mentioned above $11 \beta$-HSD2 enzyme activation is regulated by histone methylation of its gene [50]. In experimental studies on mice it has been shown that the methylation of lysine residue 79 at histone $\mathrm{H} 3$ reduces $11 \beta$-HSD2 gene expression [51]. An abnormal increase of methylation of $11 \beta$-HSD2 promotor seems to lead to hypertension. It has been shown that calcium deficiency in pregnant rats leads to a reduction of methylation $11 \beta$-HSD1 gene and glucocorticosteroid receptor NR3C1 in the offspring [52]. It is known that increased plasma cortisol concentration leads to hypertension [53]. In addition, a low protein diet 
Table I. Environmental factors affecting the foetus causes decreasing of nephron number

\begin{tabular}{|l|l|l|}
\hline Dietary factors & Drugs & Others \\
\hline Low protein intake & Glucocorticoids & Ethanol intake \\
Vitamin A deficiency & Cyclosporine A & Cigarette smoking \\
Iron deficiency & Antibiotics (gentamicin, ampicillin, amoxicillin) & \\
Zinc deficiency & & \\
High or too low sodium intake & & \\
\hline
\end{tabular}

during pregnancy causes hypomethylation of $\mathrm{AT}_{1 \mathrm{~b}}$ angiotensin receptor gene in the adrenal glands of the offspring [54].

Second mechanism of epigenetic regulation is a post-translational modification of histones (PTMs). It has been shown that histone acetylation plays a key role in the development of hypertension associated with glucocorticoids [55]. Furthermore, histone acetylation plays an important role in upregulating $11 \beta$-HSD2 activity in human placenta [56]. Glucocorticoids may program the foetus through epigenetic modifications to the development of hypertension [57]. It has been shown that dexamethasone leads to a reduction of the interferon-gamma gene expression by histone deacetylation [58]. This leads to the development of hypertension in the offspring [59].

Third mechanism of epigenetic regulation may be a regulation based on micro RNA (miRNA). These small fragments of RNA inhibits the degradation of messenger RNA (mRNA) and translation. It has been shown both in vitro and in vivo that glucocorticosteroid receptor expression and activity is reduced by miR-124 and miR-18 [60]. Other studies have demonstrated that the other types of miRNA reduce glucocorticoid receptor expression in the adrenal glands in mice [61]. These mechanisms may be also involved in pathogenesis of hypertension in the offspring.

\section{Summary}

In summary, the factors affecting the development of foetal kidneys may also predispose to the development of arterial hypertension in the adult life. For this reason, prevention against development of arterial hypertension should start already during pregnancy. The most important elements of such a prophylaxis should be balanced diet, healthy lifestyle, avoiding smoking cigarettes, alcohol consumption and drugs affecting the development of the foetal kidneys, such as corticosteroids and probably some immunosuppressive drugs or antibiotics.

\section{References}

1. Barker D.J., Osmond C. Infant mortality, childhood nutrition, and ischaemic heart disease in England and Wales. Lancet 1986; 1: 1077-1081.

2. Barker D.J., Bagby S.P., Hanson M.A. Mechanisms of disease: in utero programming in the pathogenesis of hypertension. Nat. Clin. Pract. Nephrol. 2006; 2: 700-707.

3. Mu M., Wang S.F., Sheng J. et al. Birth weight and subsequent blood pressure: a meta-analysis. Arch. Cardiovasc. Dis. 2012; 105: 99-113.

4. Rettig R., Folberth C., Stauss H. et al. Role of the kidney in primary hypertension: a renal transplantation study in rats. Am. J. Physiol. 1990; 258: 606-611.

5. Patschan O., Kuttler B., Heemann U. et al. Kidneys from normotensive donors lower blood pressure in young transplanted spontaneously hypertensive rats. Am. J. Physiol. 1997; 273: 175-180.

6. Curtis J.J., Luke R.G., Dustan H.P. et al. Remission of essential hypertension after renal transplantation. N. Engl. J. Med. 1983; 309: 1009-1015.

7. Puelles V.G., Hoy W.E., Hughson M.D. et al. Glomerular number and size variability and risk for kidney disease. Curr. Opin. Nephrol. Hypertens. 2011; 20: 7-15.

8. Keller G., Zimmer G., Mall G. et al. Nephron number in patients with primary hypertension. N. Engl. J. Med. 2003; 348: 101-108.

9. Hughson M.D., Douglas-Denton R., Bertram J.F., Hoy W.E. Hypertension, glomerular number, and birth weight in African Americans and white subjects in the southeastern United States. Kidney Int. 2006; 69: 671-678.

10. Quigley R. Developmental changes in renal function. Curr. Opin. Pediatr. 2012; 24: 184-190.

11. Mañalich R., Reyes L., Herrera M. et al. Relationship between weight at birth and the number and size of renal glomeruli in humans: a histomorphometric study. Kidney Int. 2000; 58: 770-773.

12. Hughson M., Farris A.B. 3rd, Douglas-Denton R. et al. Glomerular number and size in autopsy kidneys: the relationship to birth weight. Kidney Int. 2003; 63: 2113-2122.

13. Luyckx V.A., Bertram J.F., Brenner B.M. et al. Effect of fetal and child health on kidney development and long-term risk of hypertension and kidney disease. Lancet 2013; 382: 273-283.

14. Hoy W.E., Douglas-Denton R.N., Hughson M.D. et al. A stereological study of glomerular number and volume: preliminary findings in a multiracial study of kidneys at autopsy. Kidney Int. Suppl. 2003; 83: S31-37.

15. Keijzer-Veen M.G., Devos A.S., Meradji M. et al. Reduced renal length and volume 20 years after very preterm birth. Pediatr. Nephrol. 2010; 25: 499-507.

16. Pruijm M., Ponte B., Ackermann D. et al. Heritability, determinants and reference values of renal length: a family-based population study. Eur. Radiol. 2013; 23: 2899-2905.

17. Woods L.L., Ingelfinger J.R., Nyengaard J.R., Rasch R. Maternal protein restriction suppresses the newborn renin-angiotensin system and programs adult hypertension in rats. Pediatr. Res. 2001; 49: 460-467.

18. Woods L.L., Weeks D.A., Rasch R. Programming of adult blood pressure by maternal protein restriction: role of nephrogenesis. Kidney Int. 2004; 65: 1339-1348.

19. Bagby S.P. Maternal nutrition, low nephron number, and hypertension in later life: pathways of nutritional programming. J. Nutr. 2007; 137: 1066-1072. 
20. Burdge G.C., Slater-Jefferies J., Torrens C. et al. Dietary protein restriction of pregnant rats in the $\mathrm{F} 0$ generation induces altered methylation of hepatic gene promoters in the adult male offspring in the F1 and F2 generations. Br. J. Nutr. 2007; 97: 435-439.

21. Mesquita F.F., Gontijo J.A., Boer P.A. Maternal undernutrition and the offspring kidney: from fetal to adult life. Braz. J. Med. Biol. Res. 2010; 43: 1010-1018.

22. Lelièvre-Pégorier M., Vilar J., Ferrier M.L. et al. Mild vitamin A deficiency leads to inborn nephron deficit in the rat. Kidney Int. 1998; 54: 1455-1462.

23. Goodyer P., Kurpad A., Rekha S. et al. Effects of maternal vitamin A status on kidney development: a pilot study. Pediatr. Nephrol. 2007; 22: 209-214.

24. Lisle S.J., Lewis R.M., Petry C.J. et al. Effect of maternal iron restriction during pregnancy on renal morphology in the adult rat offspring. Br. J. Nutr. 2003; 90: 33-39.

25. Swali A., McMullen S., Hayes H. et al. Processes underlying the nutritional programming of embryonic development by iron deficiency in the rat. PLoS One 2012; 7: 48133.

26. Tomat A.L., Inserra F., Veiras L. et al. Moderate zinc restriction during fetal and postnatal growth of rats: effects on adult arterial blood pressure and kidney. Am. J. Physiol. Regul. Integr. Comp. Physiol. 2008; 295: 543-549.

27. Tomat A.L., Veiras L.C., Aguirre S. et al. Mild zinc deficiency in male and female rats: early postnatal alterations in renal nitric oxide system and morphology. Nutrition 2013; 29: 568-573.

28. Koleganova N., Piecha G., Ritz E. et al. Both high and low maternal salt intake in pregnancy alter kidney development in the offspring. Am. J. Physiol. Renal. Physiol. 2011; 301: 344-354.

29. Gray S.P., Denton K.M., Cullen-McEwen L. et al. Prenatal exposure to alcohol reduces nephron number and raises blood pressure in progeny. J. Am. Soc. Nephrol. 2010; 21: 1891-1902.

30. Gray S.P., Cullen-McEwen L.A., Bertram J.F., Moritz K.M. Mechanism of alcohol-induced impairment in renal development: Could it be reduced by retinoic acid? Clin. Exp. Pharmacol. Physiol. 2012; 39: 807-813

31. Zarzecki M., Adamczak M., Wystrychowski A. et al. Exposure of pregnant rats to cigarette-smoke condensate causes glomerular abnormalities in offspring. Kidney Blood Press. Res. 2012; 36: 162-171.

32. Geerts C.C., Grobbee D.E., van der Ent C.K. et al. Tobacco smoke exposure of pregnant mothers and blood pressure in their newborns: results from the wheezing illnesses study Leidsche Rijn birth cohort. Hypertension 2007; 50: 572-578.

33. Lawlor D.A., Najman J.M., Sterne J. et al. Associations of parental, birth, and early life characteristics with systolic blood pressure at 5 years of age: findings from the Mater-University study of pregnancy and its outcomes. Circulation 2004; 110: 2417-2423.

34. Högberg L., Cnattingius S., Lundholm C. et al. Effects of maternal smoking during pregnancy on offspring blood pressure in late adolescence. J. Hypertens. 2012; 30: 693-699.

35. Taal H.R., Geelhoed J.J., Steegers E.A. et al. Maternal smoking during pregnancy and kidney volume in the offspring: the Generation R Study. Pediatr. Nephrol. 2011; 26: 1275-1283.

36. Ortiz L.A., Quan A., Zarzar F. et al. Prenatal dexamethasone programs hypertension and renal injury in the rat. Hypertension 2003; 41: 328-334.

37. Doyle L.W., Ford G.W., Davis N.M., Callanan C. Antenatal corticosteroid therapy and blood pressure at 14 years of age in preterm children. Clin. Sci. (Lond.) 2000; 98: 137-142.

38. Wintour E.M., Moritz K.M., Johnson K. et al. Reduced nephron number in adult sheep, hypertensive as a result of prenatal glucocorticoid treatment. J. Physiol. 2003; 549: 929-935.

39. Celsi G., Kistner A., Aizman R. et al. Prenatal dexamethasone causes oligonephronia, sodium retention, and higher blood pressure in the offspring. Pediatr. Res. 1998; 44: 317-322.

40. Seckl J.R., Holmes M.C. Mechanisms of disease: glucocorticoids, their placental metabolism and fetal 'programming' of adult pathophysiology. Nat. Clin. Pract. Endocrinol. Metab. 2007; 3: 479-488.
41. Seckl J.R., Cleasby M., Nyirenda M.J. Glucocorticoids, 11 beta-hydroxysteroid dehydrogenase, and fetal programming. Kidney Int. 2000; 57: 1412-1417.

42. Langley-Evans S.C., Phillips G.J., Benediktsson R. et al. Protein intake in pregnancy, placental glucocorticoid metabolism and the programming of hypertension in the rat. Placenta 1996; 17: 169-172.

43. Slabiak-Blaz N., Adamczak M., Gut N. et al. Administration of cyclosporine A in pregnant rats - the effect on blood pressure and on the glomerular number in their offspring. Kidney Blood Press. Res. 2015; 40: 413-423.

44. Nathanson S., Moreau E., Merlet-Benichou C., Gilbert T. In utero and in vitro exposure to beta-lactams impair kidney development in the rat. J. Am. Soc. Nephrol. 2000; 11: 874-884.

45. Gilbert T., Lelievre-Pegorier M., Merlet-Benichou C. Immediate and long-term renal effects of fetal exposure to gentamicin. Pediatr. Nephrol. 1990; 4: 445-450.

46. Anwar M.A., Saleh A.I., Al Olabi R. et al. Glucocorticoid-induced fetal origins of adult hypertension: Association with epigenetic events. Vascul. Pharmacol. 2016: 1537-1891.

47. Hogg K., Blair J.D., McFadden D.E. et al. Early onset pre-eclampsia is associated with altered DNA methylation of cortisol signaling and steroidogenic genes in the placenta. PLoS One. 2013; 8: e62969.

48. Palatini P., Casiglia E., Pauletto P. et al. Relationship of tachycardia with high blood pressure and metabolic abnormalities: a study with mixture analysis in three populations. Hypertension 1997 ; 30: 1267-1273.

49. Burdge G.C., Lillycrop K.A., Phillips E.S. et al. Folic acid supplementation during the juvenile-pubertal period in rats modifies the phenotype and epigenotype induced by prenatal nutrition. J. Nutr. 2009; 139: 1054-1060.

50. Togher K.L., Togher K.L., O'Keeffe M.M. et al. Epigenetic regulation of the placental HSD11B2 barrier and its role as a critical regulator of fetal development. Epigenetics 2014; 9: 816-822.

51. Millis R.M. Epigenetics and hypertension. Curr. Hypertens. Rep. 2011; 13: 21-28.

52. Takaya J., Iharada A., Okihana H., Kaneko K. A calcium-deficient diet in pregnant, nursing rats induces hypomethylation of specific cytosines in the $11 \beta$-hydroxysteroid dehydrogenase-1 promoter in pup liver. Nutr. Res. 2013; 33: 961-970.

53. Whitworth J.A., Williamson P.M., Mangos G., Kelly J.J. Cardiovascular consequences of cortisol excess. Vasc. Health Risk Manag. 2005; 1: 291-299.

54. Bogdarina I., Welham S., King P.J. et al. Epigenetic modification of the renin-angiotensin system in the fetal programming of hypertension. Circ. Res. 2007; 100: 520-526.

55. Stratton M.S., McKinsey T.A. Acetyl-lysine erasers and readers in the control of pulmonary hypertension and right ventricular hypertrophy. Biochem. Cell Biol. 2015; 93: 149-157.

56. Li J., Wang W., Liu C. et al. Critical role of histone acetylation by p300 in human placental $11 \beta$-HSD2 expression. J. Clin. Endocrinol. Metab. 2013; 98: 1189-1197.

57. Thompson L.P., Al-Hasan Y. Impact of oxidative stress in fetal programming. J. Pregnancy 2012; 2012: 582748.

58. Krukowski K., Eddy J., Kosik K.L. et al. Glucocorticoid dysregulation of natural killer cell function through epigenetic modification. Brain Behav. Immun. 2011; 25: 239-249.

59. Ishimitsu T., Uehara Y., Numabe A. et al. Interferon gamma attenuates hypertensive renal injury in salt-sensitive Dahl rats. Hypertension 1992; 19: 804-808.

60. Vreugdenhil E., Verissimo C.S., Mariman R. et al. MicroRNA 18 and 124a down-regulate the glucocorticoid receptor: implications for glucocorticoid responsiveness in the brain. Endocrinology 2009; 150: $2220-2228$.

61. Riester A., Issler O., Spyroglou A. et al. ACTH-dependent regulation of microRNA as endogenous modulators of glucocorticoid receptor expression in the adrenal gland. Endocrinology 2012; 153: 212-222.

62. Lisle S.J., Lewis R.M., Petry C.J et al. Effect of maternal iron restriction during pregnancy on renal morphology in the adult rat offspring. Br. J. Nutr. 2003; 90: 33-39. 